Volume 8, No.1.6, 2019

International Journal of Advanced Trends in Computer Science and Engineering

Available Online at http://www.warse.org/IJATCSE/static/pdf/file/ijatcse3781.62019.pdf

https://doi.org/10.30534/ijatcse/2019/3781.62019

\title{
Optimal Power Scheduling Strategy in Power Systems using Swarm Optimization Technique
}

\author{
Nor Azwan Mohamed Kamari ${ }^{1}$, Nur Azzammudin Rahmat ${ }^{2}$, Ismail Musirin ${ }^{3}$ \\ ${ }^{1}$ Centre for Integrated Systems Engineering and Advanced Technologies (Integra), \\ Department of Electrical, Electronic and System Engineering, \\ Faculty of Engineering and Built Environment, Universiti Kebangsaan Malaysia, \\ 43600 Bangi, Selangor, Malaysia, azwank@ukm.edu.my \\ ${ }^{2}$ Department of Electrical Power Engineering, Universiti Tenaga Nasional, \\ 43000 Kajang, Selangor, Malaysia, azzammudin@uniten.edu.my \\ ${ }^{3}$ Faculty of Electrical Engineering, Universiti Teknologi MARA, 40450 Shah Alam, \\ Selangor, Malaysia, ismailbm@ @alam.uitm.edu.my
}

\begin{abstract}
This study proposes a power scheduling strategy for power system networks by using PSO technique. This strategy searches for the optimal power for each generating unit in the system, without compromising the total power demands and constraints of each unit. The objective function aims to minimize the total generation cost. The amount of power loss is measured to determine the feasibility of the proposed technique. In addition, optimization processes using evolutionary programming (EP) and artificial immune system (AIS) are implemented. Five- and 30-bus power system networks are selected and processed using MATLAB. The simulation results indicate that PSO performs better than EP and AIS in determining the optimal power generation value with minimum generation cost and power loss.
\end{abstract}

Key words: economic dispatch, particle swarm optimization, artificial immune system, evolutionary programming

\section{INTRODUCTION}

Nowadays, smart grid initiatives have been adopted by most developed countries to achieve a sustainable grid system. This system integrates conventional energy carriers (e.g., coal and petroleum) with renewable energy carriers, such as photovoltaic cells and battery energy storage. One of the foci in smart grid research is the selection of suitable operated energy carriers for the entire power generating units. The large distance of the power generating unit from the load in the power grid can result in high generation costs. Nevertheless, this power scheduling problem can be solved by calculating the economic load dispatch (ELD).

The objective of ELD is to determine the optimum power generating unit for minimizing the total generation cost producing power according to the power demands and constraints of each generating unit. Various mathematical programming and optimization techniques have been utilized to solve this problem. ELD problems are originally solved using traditional calculation methods. However, these methods have long implementation times, cannot solve non-linear cost functions, and hardly obtain optimal solutions. These disadvantages result in the use of heuristic techniques to solve ELD engineering problems [1-6] [16-18].

Among the AI approaches that have been introduced to solve optimization problems in power systems are evolutionary programming (EP) [6-11], artificial immune systems (AIS) [12-15], and ant colony optimization (ACO) [16-19]. The EP algorithm is modeled on the biological evolution process of solving a complex problem. The main features of EP include the mutation process of the next generation and the selection of increasingly powerful genes. The AIS algorithm uses a concept similar to EP. However, the latter focuses on the evolution of living things, whereas the former adopts the concept of the living immune system. In addition, AIS has an additional process of cloning called the clonal selection algorithm. The ACO approach is inspired by the true behavior of ants when searching for food and interacting with fellow ants. In ACO, artificial ants (i.e., the search agent) can communicate using pheromones, which guide the searcher ants to solve the calculation problem by tracking the best route. The particle swarm optimization (PSO) [20]-[26] concept mimics the movements of a herd, such as the behavior of schooling fish and swarming insects. This technique was originally founded on the basis of the population of random particles, in which every particle is a potential solution. PSO can make adjustments to obtain a balance between global and local explorations during the search process. This feature renders the PSO suitable in overcoming the problems caused by initial convergence and improving the searching ability.

To meet the required power demand, this study proposes an efficient technique for calculating the optimum power generating capacity of each power generation unit by using $\mathrm{EP}$, AIS, and PSO. The research aims to minimize the total 
power generation cost. Two main simulation events have been performed. In Event 1, a five-bus system with three power generation units is simulated under three different power demands: 90, 150, and 180 MW. In Event 2, a 30-bus system with six power generation units is simulated under 650, 870, and $1100 \mathrm{MW}$.

The rest of the paper is organized as follows: Section 2 presents the basic calculation of ELD. Section 3 explains the problem formulation for the three optimization techniques (PSO, EP, and AIS) and the optimal power scheduling algorithms. Section 4 provides the simulation results and discussions. Lastly, Section 5 presents the conclusions.

\section{ELD PROBLEM FORMULATION}

By using the available power generating units, the objective function of ELD aims to economically schedule power production according to the given operating conditions and constraints. The total production $\operatorname{cost} C_{T}$ of one power system network can be expressed as

$$
C_{T}=\sum_{i=1}^{n} C_{i}\left(P_{i}\right),
$$

where $C_{T}$ is the total production cost, $C_{i}\left(P_{i}\right)$ is the production cost of the $i^{\text {th }}$ generating unit, and $n$ is number of the generating units in the system. Objective function $J$ can be written as

$$
J=\text { Minimize } C_{T} \text {. }
$$

The production cost function of a single generating unit consists of fuel cost coefficients and the corresponding real power outputs. $C_{i}\left(P_{i}\right)$ can be represented as a quadratic function.

$$
C_{i}\left(P_{i}\right)=a_{i}+b_{i} \cdot P_{i}+c_{i} \cdot P_{i}^{2},
$$

where $a_{i}, b_{i}$, and $c_{i}$ are the fuel cost coefficients for the $i^{\text {th }}$ generating unit.

To optimize the objective function, two constraints must be considered: the operating limits of the generating units and the power balance constraint.

\subsection{Operating Limits of the Generating Units}

Each generating unit has a unique cost function, and the operating limits can be written as

$$
P_{i, \min } \leq P_{i} \leq P_{i, \max }
$$

where $P_{i, \min }$ and $P_{i, \max }$ are the minimum and maximum operating limits of the $i^{\text {th }}$ generating unit, respectively.

\subsection{Power Balance Constraint}

The power generated by a generation unit should always suffice the power demand. The amount of power generated by all generation units $P_{G}$ must be equal to the sum of the total power loss in system $P_{L}$ and power demand $P_{D}$.

$$
P_{G}=\sum_{i=1}^{n} P_{i}=P_{L}+P_{D} \text {. }
$$

\section{COMPUTATIONAL INTELLIGENCE METHODS FOR POWER SCHEDULING}

In recent years, Artificial Intelligence (AI) technology has been widely used in solving optimization problems in power systems. Evolutionary computation (EC) is a widely used AI technique that models evolutionary processes to develop the strategies for determining the optimal or almost optimal solutions for specific problems. Examples of EC techniques include EP, genetic algorithm, AIS, and PSO. In this study, AIS, EP, and PSO are selected as the optimization techniques.

\subsection{Algorithm for the Optimal Power Scheduling}

To find the minimum $C_{T}$, the optimization process for the power generated by the $i^{\text {th }}$ power generating unit $P_{i}$ is conducted repeatedly. The optimization process is explained below.

(i.) Determine the $P_{i}$ value using EP, AIS, or PSO optimization techniques with the given power constraint limit $\left(P_{i, \min }\right.$ and $\left.P_{i, \max }\right)$ for each power generation unit, as shown in Equation (4). Subsequently, calculate the total power loss $P_{L}$ under $2 \mathrm{MW}$ by using Equation (5).

(ii.) Calculate $C_{T}$ using Equations (1) and (3).

(iii.) Evaluate the values of the selected parameters and repeat Steps (i) and (ii) until the difference between the maximum $\left(J_{\max }\right)$ and minimum $\left(J_{\min }\right)$ values of the objective function reaches 0.001 or the number of iterations reaches 100 .

\subsection{EP}

The concept of EP is based on the theory of life evolution through natural selection. EP is motivated by the process at the evolution stage (i.e., parents, mutation, and offspring) without the genetic evolution. The EP algorithm begins with the initialization, followed by the determination of fitness, mutations, combinations of parent and offspring, and ends with the selection. Figure 1 illustrates the pseudocode for the algorithm [27].

In Figure $1, l$ is the number of generations; $j$ is the number of populations; $\alpha$ is a mutation factor in EP; and $x_{i, p a r}$ and $x_{i, o f f}$ are the parents and offspring for the $j^{\text {th }}$ population, respectively. 


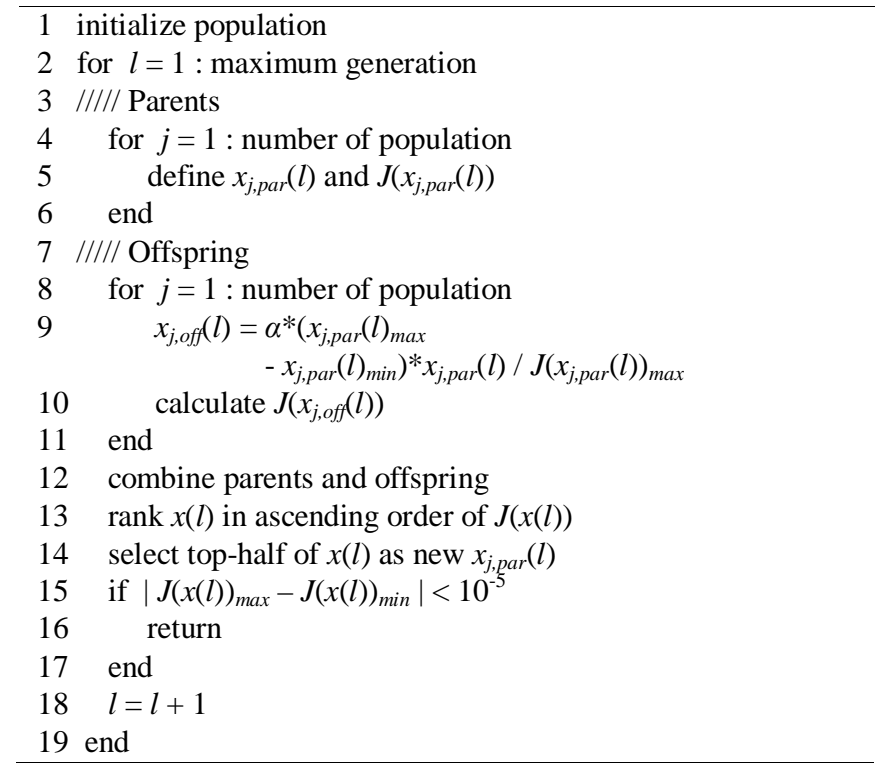

Figure 1: Pseudocode for the EP algorithm

\subsection{AIS}

AIS is an optimization technique that attempts to biologically imitate the human immune system. This concept is almost similar to EP, except that AIS has an additional criterion called cloning. The entire process is presented in Figure 2 [28].

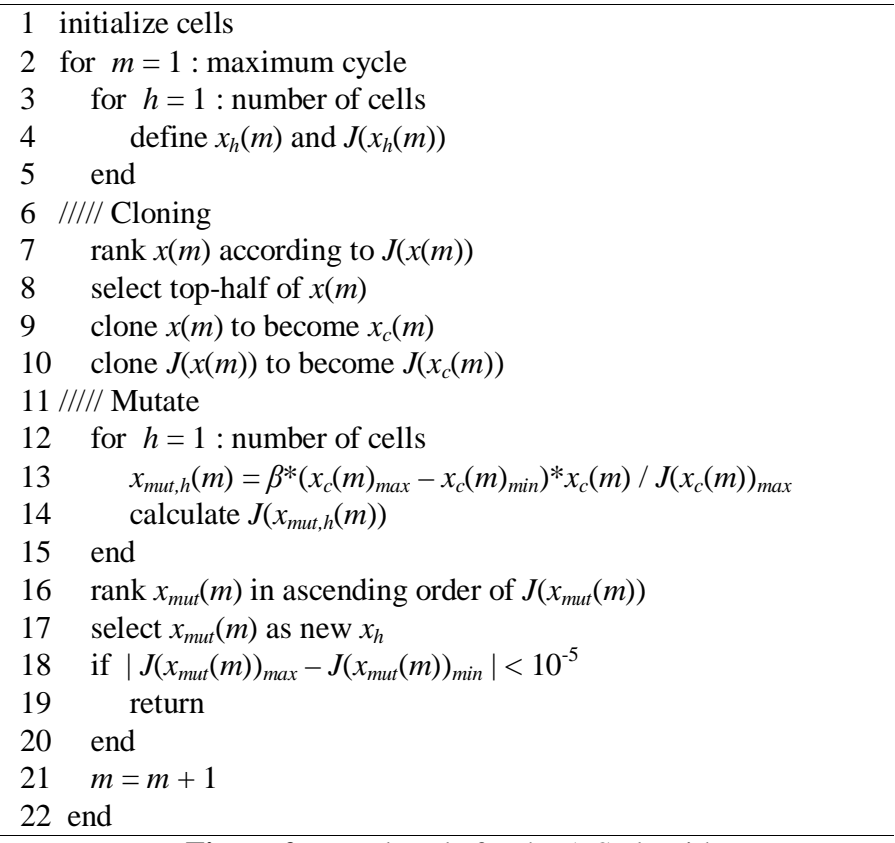

Figure 2: Pseudocode for the AIS algorithm

In Figure 2, $m$ is the number of cycles, $h$ is the number of cells, $\beta$ is a mutation factor in AIS, $x_{h}$ is the pre-cloning of the $h^{\text {th }}$ cells, $x_{c}$ is the post-cloning cells, and $x_{m u t h}$ is the mutated $h^{\text {th }}$ cells.

\subsection{PSO}

As previously mentioned, PSO technique is inspired by the feeding process of certain animals. This algorithm begins with initialization, followed by the update of velocity and position, fitness calculation, best position update, and convergence test. The pseudocode that represents the PSO algorithm is illustrated in Figure 3. The detailed explanations of the PSO algorithm process can be found in [29].

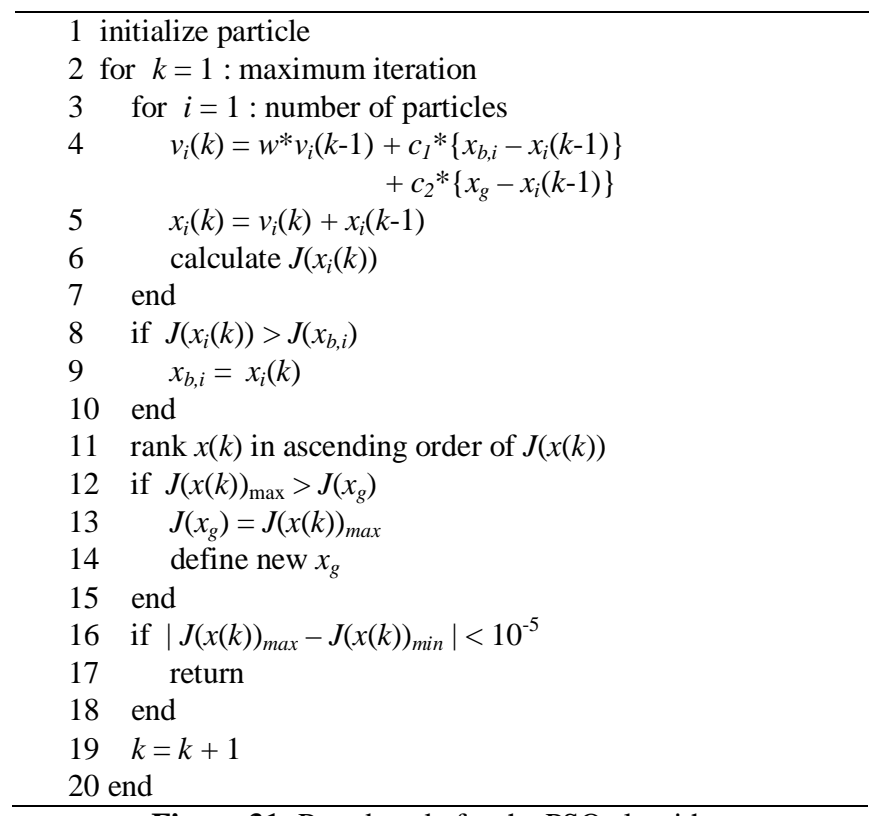

Figure 31: Pseudocode for the PSO algorithm

In Figure 3, $k$ is the number of iterations; $i$ is the number of particles; $\omega$ is the inertia weight; $v_{i}$ and $x_{i}$ are the velocity and position for the $i^{\text {th }}$ particle, respectively. $c_{1}$ and $c_{2}$ are the acceleration coefficients, $J$ is the objective function, $x_{b, i}$ is the personal best position for the $i^{\text {th }}$ particle, and $x_{g}$ is the global best position.

In this study, the value of $x$ is taken as the output generator $P$ for ELD computation. While, the total power production cost $C_{T}$ is set as objective function $J$. With the implementation of this optimization technique, $C_{T}$ and total power loss $P_{L}$ can be minimized, without prejudice to the requirements of power demand $P_{D}$.

The list of parameters used in all three optimization techniques are tabulated in Table 1.

Table 1: List of parameters used in PSO, EP, and AIS

\begin{tabular}{|c|c|}
\hline Technique & Parameter \\
\hline PSO & $C_{l}=0.5, C_{2}=0.5, \omega=0.05$ \\
\hline EP & $\alpha=0.05$ \\
\hline AIS & $\beta=0.05$ \\
\hline
\end{tabular}




\section{RESULTS AND DISCUSSION}

In this study, two simulation events with three cases each were performed and evaluated. Event 1 used a five-bus system with three generators (Cases 1-A, 1-B, and 1-C), whereas Event 2 used a 30-bus system with six generators (Cases 2-A, $2-\mathrm{B}$, and 2-C). Table 2 presents all the events and cases conducted under the power demand constraints.

Table 2: List of events, cases, and power demands

\begin{tabular}{|c|c|c|c|}
\hline Event & Test System & Case & Power Demand \\
\hline \multirow{3}{*}{ Event 1} & \multirow{3}{*}{$\begin{array}{l}\text { five-bus system } \\
\text { with three } \\
\text { generators }\end{array}$} & Case 1-A & $90 \mathrm{MW}$ \\
\hline & & Case 1-B & $150 \mathrm{MW}$ \\
\hline & & Case 1-C & $180 \mathrm{MW}$ \\
\hline \multirow{3}{*}{ Event 2} & \multirow{3}{*}{$\begin{array}{l}\text { 30-bus system } \\
\text { with six } \\
\text { generators }\end{array}$} & Case 2-A & $650 \mathrm{MW}$ \\
\hline & & Case 2-B & $870 \mathrm{MW}$ \\
\hline & & Case 2-C & $1100 \mathrm{MW}$ \\
\hline
\end{tabular}

\subsection{Event 1}

The fuel cost coefficients $\left(a_{i}, b_{i}\right.$, and $\left.c_{i}\right)$ and minimum and maximum power limits for each generator are presented in Table 3 [30].

Table 3: Fuel cost coefficients and power limits for Event 1

\begin{tabular}{|c|c|c|c|c|c|}
\hline Unit & $\begin{array}{c}a_{i} \\
(\mathrm{MW})^{2}\end{array}$ & $\begin{array}{c}b_{i} \\
(\mathrm{MW})\end{array}$ & $c_{i}$ & $\begin{array}{c}P_{\min } \\
(\mathrm{MW})\end{array}$ & $\begin{array}{c}P_{\max } \\
(\mathrm{MW})\end{array}$ \\
\hline 1 & 200 & 7.0 & 0.008 & 10 & 85 \\
\hline 2 & 180 & 6.3 & 0.009 & 10 & 80 \\
\hline 3 & 140 & 6.8 & 0.007 & 10 & 70 \\
\hline
\end{tabular}

The simulation for the three cases was performed using MATLAB. The optimization that uses the EP, AIS, and PSO was performed separately.

The results for the generating value of each generator unit $\left(P_{I}-P_{3}\right), P_{G}, P_{L}$, and $C_{T}$ using the three optimization techniques for Case 1-A are tabulated in Table 4.

Table 4: Power scheduling for Case 1-A $\left(P_{D}=90 \mathrm{MW}\right)$

\begin{tabular}{|c|c|c|c|}
\hline Method & PSO & EP & AIS \\
\hline$P_{I}(\mathrm{MW})$ & 12.1489 & 12.0282 & 23.0608 \\
\hline$P_{2}(\mathrm{MW})$ & 49.6840 & 45.8932 & 41.6314 \\
\hline$P_{3}(\mathrm{MW})$ & 28.1672 & 32.1321 & 25.9750 \\
\hline$P_{G}(\mathrm{MW})$ & 90.0000 & 90.0535 & 90.6672 \\
\hline$P_{L}(\mathrm{MW})$ & 0.0000 & 0.0535 & 0.6672 \\
\hline$C_{T}(\$ / \mathrm{h})$ & 1138.50 & 1139.20 & 1144.90 \\
\hline
\end{tabular}

For Case 1-A, the simulation results using the PSO approach yield the lowest generation cost $(\$ 1138.50 / \mathrm{h})$, followed by EP and then AIS. From the perspective of the generated power, AIS generates the highest power loss among the three methods $(0.6672 \mathrm{MW})$, whereas PSO results in zero power loss. Based on these results, the PSO method can obtain the least power generation costs and power loss among the three techniques.
Table 5 shows the results of the three optimization techniques for Case 1-B. In this case, the optimization results of the three techniques for the generation costs are almost identical. PSO is $\$ 0.20 / \mathrm{h}$ cheaper than EP, whereas AIS is $\$ 0.50 / \mathrm{h}$ more expensive than EP. In terms of $P_{L}$, PSO results in zero power loss, whereas EP and AIS produce 0.0238 and $0.0950 \mathrm{MW}$, respectively.

The results for Case 1-C (Table 6) are very similar to those for Cases 1-A and 1-B. Therefore, PSO technique can provide lower power generation costs and power loss than those of AIS and EP.

Table 5: Power scheduling for Case 1-B $\left(P_{D}=150 \mathrm{MW}\right)$

\begin{tabular}{|c|c|c|c|}
\hline Method & PSO & EP & AIS \\
\hline$P_{l}(\mathrm{MW})$ & 31.9344 & 30.8459 & 30.8584 \\
\hline$P_{2}(\mathrm{MW})$ & 67.2761 & 67.0228 & 67.0383 \\
\hline$P_{3}(\mathrm{MW})$ & 50.7895 & 52.1551 & 52.1983 \\
\hline$P_{G}(\mathrm{MW})$ & 150.0000 & 150.0238 & 150.0950 \\
\hline$P_{L}(\mathrm{MW})$ & 0.0000 & 0.0238 & 0.0950 \\
\hline$C_{T}(\$ / \mathrm{h})$ & 1579.70 & 1579.90 & 1580.40 \\
\hline
\end{tabular}

Table 6: Power scheduling for Case 1-C $\left(P_{D}=210 \mathrm{MW}\right)$

\begin{tabular}{|c|c|c|c|}
\hline Method & PSO & EP & AIS \\
\hline$P_{I}(\mathrm{MW})$ & 54.2983 & 64.9271 & 65.0675 \\
\hline$P_{2}(\mathrm{MW})$ & 82.1213 & 77.5481 & 77.6478 \\
\hline$P_{3}(\mathrm{MW})$ & 73.5803 & 67.8701 & 67.9878 \\
\hline$P_{G}(\mathrm{MW})$ & 210.0000 & 210.3453 & 210.7031 \\
\hline$P_{L}(\mathrm{MW})$ & 0.0000 & 0.3453 & 0.7031 \\
\hline$C_{T}(\$ / \mathrm{h})$ & 2040.00 & 2044.70 & 2047.50 \\
\hline
\end{tabular}

\subsection{Event 2}

Table 7 presents the fuel cost coefficients and power limits for each generator in Event 2 [30].

Table 7: Fuel cost coefficients and power limits for Event 2

\begin{tabular}{|c|c|c|c|c|c|}
\hline Unit & $\begin{array}{c}a_{i} \\
(\mathrm{MW})^{2}\end{array}$ & $\begin{array}{c}b_{i} \\
(\mathrm{MW})\end{array}$ & $c_{i}$ & $\begin{array}{c}P_{\min } \\
(\mathrm{MW})\end{array}$ & $\begin{array}{c}P_{\max } \\
(\mathrm{MW})\end{array}$ \\
\hline 1 & 240 & 7.0 & 0.0070 & 100 & 500 \\
\hline 2 & 200 & 10.0 & 0.0095 & 50 & 200 \\
\hline 3 & 220 & 8.5 & 0.0090 & 80 & 300 \\
\hline 4 & 200 & 11.0 & 0.0090 & 50 & 150 \\
\hline 5 & 220 & 10.5 & 0.0080 & 50 & 200 \\
\hline 6 & 190 & 12.0 & 0.0075 & 50 & 120 \\
\hline
\end{tabular}

The results for the power generated by each generator unit $\left(P_{I}-P_{6}\right), P_{G}, P_{L}$, and $C_{T}$ for Case 2-A are presented in Table 8 . On the basis of the given data, the $P_{1}-P_{6}$ values calculated using EP and AIS techniques are similar, whereas the results calculated using PSO greatly differs from the two other methods. This finding indicates that the search results using PSO are not limited to the local maximum or minimum of generation cost but are rather beyond the capability of EP and AIS to obtain optimal values. The PSO yields a generation cost of $\$ 7697.80 / \mathrm{h}$, which is lower than that of the EP $(\$ 7763.30 / \mathrm{h})$ and AIS $(\$ 7767.60 / \mathrm{h})$. In terms of power loss, 
the AIS technique generates the highest power loss among the three, exceeding 0.54 MW. EP and PSO result in the power loss of 0.0721 and $0.0073 \mathrm{MW}$, respectively.

Table 9 shows the results for Case 2-B, wherein PSO obtains the cheapest generation cost, followed by EP and AIS. In terms of $P_{L}$, PSO generates zero power loss, whereas AIS produces the highest power loss among the three $(0.7148$ MW).

Table 8: Power scheduling for Case 2-A $\left(P_{D}=650 \mathrm{MW}\right)$

\begin{tabular}{|c|c|c|c|}
\hline Method & PSO & EP & AIS \\
\hline$P_{l}(\mathrm{MW})$ & 289.5087 & 263.3965 & 263.5085 \\
\hline$P_{2}(\mathrm{MW})$ & 64.4663 & 82.6302 & 82.7108 \\
\hline$P_{3}(\mathrm{MW})$ & 143.5901 & 110.1127 & 110.2651 \\
\hline$P_{4}(\mathrm{MW})$ & 50.7748 & 61.4366 & 61.4781 \\
\hline$P_{5}(\mathrm{MW})$ & 51.6650 & 67.4846 & 67.5125 \\
\hline$P_{6}(\mathrm{MW})$ & 50.0024 & 65.0115 & 65.0657 \\
\hline$P_{G}(\mathrm{MW})$ & 650.0073 & 650.0721 & 650.5407 \\
\hline$P_{L}(\mathrm{MW})$ & 0.0073 & 0.0721 & 0.5407 \\
\hline$C_{T}(\$ / \mathrm{h})$ & 7697.80 & 7762.30 & 7767.60 \\
\hline
\end{tabular}

Table 9: Power scheduling for Case 2-B $\left(P_{D}=870 \mathrm{MW}\right)$

\begin{tabular}{|c|c|c|c|}
\hline Method & PSO & EP & AIS \\
\hline$P_{l}(\mathrm{MW})$ & 357.8642 & 336.9724 & 336.9814 \\
\hline$P_{2}(\mathrm{MW})$ & 108.2667 & 104.8276 & 104.9186 \\
\hline$P_{3}(\mathrm{MW})$ & 192.7798 & 179.2115 & 179.2924 \\
\hline$P_{4}(\mathrm{MW})$ & 66.5846 & 98.7100 & 98.7967 \\
\hline$P_{5}(\mathrm{MW})$ & 94.5039 & 89.6170 & 89.6635 \\
\hline$P_{6}(\mathrm{MW})$ & 50.0029 & 61.0416 & 61.0622 \\
\hline$P_{G}(\mathrm{MW})$ & 870.0000 & 870.3802 & 870.7148 \\
\hline$P_{L}(\mathrm{MW})$ & 0.0000 & 0.3802 & 0.7148 \\
\hline$C_{T}(\$ / \mathrm{h})$ & 10253.50 & 10287.85 & 10291.93 \\
\hline
\end{tabular}

For Case 2-C, the PSO remains at the forefront of producing the lowest power generation cost and the lowest power loss among the three techniques.

Table 10: Power scheduling for Case 2-C $\left(P_{D}=1100 \mathrm{MW}\right)$

\begin{tabular}{|c|c|c|c|}
\hline Method & PSO & EP & AIS \\
\hline$P_{l}(\mathrm{MW})$ & 412.3139 & 458.8306 & 423.4924 \\
\hline$P_{2}(\mathrm{MW})$ & 150.1052 & 163.0400 & 101.2801 \\
\hline$P_{3}(\mathrm{MW})$ & 240.2467 & 193.1563 & 248.8374 \\
\hline$P_{4}(\mathrm{MW})$ & 98.7647 & 78.5076 & 91.0459 \\
\hline$P_{5}(\mathrm{MW})$ & 144.1501 & 146.9723 & 136.7647 \\
\hline$P_{6}(\mathrm{MW})$ & 54.4196 & 59.5111 & 98.9789 \\
\hline$P_{G}(\mathrm{MW})$ & 1100.0002 & 1100.0179 & 1100.3994 \\
\hline$P_{L}(\mathrm{MW})$ & 0.0002 & 0.0179 & 0.3994 \\
\hline$C_{T}(\$ / \mathrm{h})$ & 13112.14 & 13151.80 & 13155.51 \\
\hline
\end{tabular}

\section{CONCLUSION}

This study proposes a power scheduling strategy on the basis of PSO to achieve the optimal power of the generating units. Two systems with three cases each are selected as test systems and are run using MATLAB. The results indicate that unlike
AIS and EP, PSO can determine the optimum power for each generating unit without being limited to the local minimum or maximum generation cost. In addition, PSO obtains the lowest generation cost among the three methods. In most cases, PSO also generates zero power loss. In conclusion, PSO is ideal in preparing the power scheduling in power system networks.

\section{ACKNOWLEDGMENT}

This study is funded by the Ministry of Education Malaysia (FRGS/1/2018/TK04/UKM/02/7).

\section{REFERENCES}

1. K. Lakshmi and S. Vasantharathna. Hybrid artificial immune system approach for profit-based unit commitment problem, Journal of Electrical Engineering and Technology, Vol. 8, No. 5, pp. 959-968, Sept. 2013.

https://doi.org/10.5370/JEET.2013.8.5.959

2. N. A. M. Din, R. H. Salimin, I. Musirin and N. M. S. Honnoon. Solving economic load dispatch for power generation using genetic algorithm techniques, International Journal of Advanced Trends in Computer Science and Engineering, Vol. 8, No. 1.3, pp. 337-344, 2019. https://doi.org/10.30534/ijatcse/2019/6181.32019

3. M. S. Ahmed, A. Mohamed, R. Z. Homod and H. Shareef. Hybrid LSA-ANN based home energy management scheduling controller for residential demand response strategy, Energies, Vol. 9, No. 9, pp. en9090716, Sept. 2016.

4. N. M. M. Farid, I. Musirin, N. H.S. Hannon, M. Amroune, Z. Othman, M. M. Othman, S. A. Shaaya, M. K. M. Zamani and N. Aminuddin. Evolutionary symbiotic organisms search technique in power scheduling for loss control in power transmission system, International Journal of Advanced Trends in Computer Science and Engineering, Vol. 8, No. 1.3, pp. 431-437, 2019.

https://doi.org/10.30534/ijatcse/2019/7481.32019

5. Z. Huang, Z. Ga, L. Qi and H. Duan. A heterogeneous evolving cuckoo search algorithm for solving large-scale combined heat and power economic dispatch problems, IEEE Access, Vol. 7, pp. 111287-111301, Aug. 2019.

6. S. Ma, Y. Wang and Y. Lv. Multiobjective environment/economic power dispatch using evolutionary multiobjective optimization, IEEE Access, Vol. 6, pp. 13066-13074, Jan. 2018. https://doi.org/10.1109/ACCESS.2018.2795702

7. A. F. A. Kadir, A. Mohamed, H. Shareef and M. Z. C. Wanik. Optimal placement and sizing of distributed generations in distribution systems for minimizing losses and THDv using evolutionary programming, Turkish Journal of Electrical Engineering and Computer Sciences, Vol. 21, No. 2, pp. 2269-2282, Oct. 2013.

8. M. Zemzami, N. Elhami, M. Itmi and N. Hmina. An evolutionary hybrid algorithm for complex 
optimization problems, International Journal of Advanced Trends in Computer Science and Engineering, Vol. 8, No. 2, pp. 126-133, March 2019. https://doi.org/10.30534/ijatcse/2019/05822019

9. L. Wang, Q. Zhang, A. Zhou, M. Gong and L. Jiao. Constrained subproblems in a decomposition-based multiobjective evolutionary algorithm, IEEE Transactions on Evolutionary Computation, Vol. 20, No. 3, pp. 475-480, June 2016.

10. C. Zhu, L. Xu and E. D. Goodman. Generalization of pareto-optimality for many-objective evolutionary optimization, IEEE Transactions on Evolutionary Computation, Vol. 20, No. 2, pp. 299-315, Apr. 2016.

11. N. A. M. Kamari, I. Musirin and M. M. Othman. Application of evolutionary programming in the assessment of dynamic stability, in 4th International Power Engineering and Optimization Conference (PEOCO), Malaysia, 2010, pp. 43-48.

12. G. Dudek. Artificial immune system with local feature selection for short-term load forecasting, IEEE Transactions on Evolutionary Computation, Vol. 21, No. 1, pp. 116-130, Feb. 2017.

13. A. A. Ibrahim, A. Mohamed, H. Shareef and S. P. Ghoshal. Optimal power quality monitor placement in power systems based on particle swarm and artificial immune system, in $3^{\text {rd }}$ Conference on Data Mining and Optimization, Putrajaya, 2011, pp. 141-145.

https://doi.org/10.1109/DMO.2011.5976518

14. R. Gonçalves, C. Almeida, M. Goldbarg, E. Goldbarg and M. Delgado. Improved cultural immune systems to solve the economic load dispatch problems, in IEEE Congress on Evolutionary Computation, Cancun, 2013, pp. 621-628.

15. S. H. Mohammad, M. H. Mansor, I. Musirin, M. N. Abdullah, S. A. Shaaya, N. A. Rahmat, M. S. A. Rahman and N. S. Razali. Economic dispatch of generators with valve-point loading effect using immune evolutionary programming, in AIP Conference Proceedings, Malaysia, 2018, pp. 020246(1-5).

16. N. A. Rahmat and I. Musirin. Differential evolution immunized ant colony optimization technique in solving economic load dispatch problem, Engineering, Vol. 5, No. 1, pp. 157-162, Jan. 2013.

17. Z. A. Hamid, I. Musirin, M. N. A. Rahim and N. A. M. Kamari. Application of electricity tracing theory and hybrid ant colony algorithm for ranking bus priority in power system, International Journal of Electrical Power \& Energy Systems, Vol. 43, No. 1, pp. 1427-1434, Dec. 2012.

18. R. Sirjani, A. Mohamed and H. Shareef. Optimal capacitor placement in distribution systems using ant colony optimization, in Regional Engineering Postgraduate Conference (EPC), Bangi, 2010, pp. 152-158.

19. K. Rayudu, G. Yesuratnam and A. Jayalaxmi. Ant colony optimization algorithm based optimal reactive power dispatch to improve voltage stability, in International Conference on Circuit, Power and Computing Technologies (ICCPCT), Kollam, 2017, pp. $1-6$.
20. H. Li, D. Yang, W. Su, J. Lü and X. Yu. An overall distribution particle swarm optimization MPPT algorithm for photovoltaic system under partial shading, IEEE Transactions on Industrial Electronics, Vol. 66, No. 1, pp. 265-275, April 2018.

21. P. T. Sawant and C.L. Bhattar. Optimization of PV system using particle swarm algorithm under dynamic weather conditions, in IEEE 6th International Conference on Advanced Computing (IACC), Bhimavaram, 2016, pp. 208-213.

22. M. Eslami, H. Shareef, M. R. Taha and M. Khajehzadeh. Adaptive particle swarm optimization for simultaneous design of UPFC damping controllers, International Journal of Electrical Power \& Energy Systems, Vol. 57, pp. 116-126, May 2014.

23. A. H. Hamdan, F. H. Hashim, A. Z. Mohamed, W. M. D. W. Zaki and A. Hussain. Modified particle swarm optimization with novel modulated inertia for velocity update, International Journal of Engineering and Technology, Vol. 8, No. 4, pp. 1855-1860, Sept. 2016. https://doi.org/10.21817/ijet/2016/v8i4/160804011

24. C. Sompracha, D. Jayaweera and P. Tricoli. Particle swarm optimization technique to improve energy efficiency of doubly-fed induction generators for wind turbines, The Journal of Engineering, Vol. 2019, No. 18, pp. 4890-4895, Aug. 2019.

25. M. Zemzami, A. Koulou, N. Elhami, M. Itmi and N. Hmina. Interoperability optimization using a modified PSO algorithm, International Journal of Advanced Trends in Computer Science and Engineering, Vol. 8, No. 2, pp. 101-107, March 2019. https://doi.org/10.30534/ijatcse/2019/01822019

26. M. M. Hoque, M. A. Hannan and A. Mohamed. Charging and discharging model of lithium-ion battery for charge equalization control using particle swarm optimization algorithm, Journal of Renewable and Sustainable Energy, Vol. 8, pp. 065701, Nov. 2016.

27. N. A. M. Kamari, I. Musirin, Z. A. Hamid and M. N. A. Rahim. An evolutionary algorithm approach to design SVC-PI controller for angle stability improvement, in International Conference on Innovation Management and Technology Research, Melaka, 2012, pp. 733-738.

28. F. R. Alonso, D. Q. Oliveira and A. C. Zambroni de Souza. Artificial immune systems optimization approach for multiobjective distribution system reconfiguration, IEEE Transactions on Power Systems, Vol. 30, No. 2, pp. 840-847, Mar. 2015. https://doi.org/10.1109/TPWRS.2014.2330628

29. N. A. M. Kamari, I. Musirin, Z. A. Hamid and M. H. M. Zaman. Oscillatory stability prediction using PSO based synchronizing and damping torque coefficients, Bulletin of Electrical Engineering and Informatics, Vol. 7, No. 3, pp. 331-344, Sept. 2018.

30. H. Saadat. Power System Analysis, 3rd ed. New York, U.S.A.: PSA Publishing, 2011, ch. 7, pp. 257-313. 